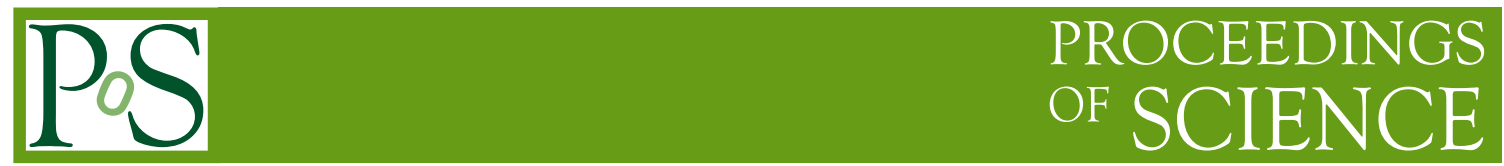

\title{
Quantum Kate - a model for physics outreach
}

\author{
Benjamin Jäger*, Sofie Gregersen, Claudio Pica, Francesco Sannino \\ CP3-Origins \& Danish IAS, University of Southern Denmark, Campusvej 55, 5230 Odense M, \\ Denmark \\ E-mail: jaeger@cp3.sdu.dk, gregersen@cp3.sdu.dk, pica@cp3.sdu.dk, \\ sanninodcp3.sdu.dk
}

\begin{abstract}
Quantum Kate is a typical teenager and youtuber, who explains concepts that are fundamental in physics, such as what are atoms made of and what is the Standard Model of particle physics, to name a few. The idea to have a youtuber as Quantum Kate is to meet young teenagers in their environment and on their premises.
\end{abstract}

The 36th Annual International Symposium on Lattice Field Theory - LATTICE2018

22-28 July, 2018

Michigan State University, East Lansing, Michigan, USA.

${ }^{*}$ Speaker. 


\section{Introduction}

Fundamental research is the pillar of innovation, but it is often seen as an ivory tower by most. On the other hand, inviting the younger generations to be part of the scientific advancements is paramount to, one day, help them contribute solving the ever growing challenges that our society faces, and to be able to discern facts from fiction.

This, however, is more easily said than done. The key question is: How do we get children and teenagers interested and excited about science and more specifically about physics? Clearly the competition for attention is fierce given the invasive presence of social media and the ever growing number of fast food entertainment shows such as X-factor, etc. Within the Quantum Rascals outreach project we therefore tried a new way to approach our audience. Quantum Rascals see the world through their eyes and use their language.

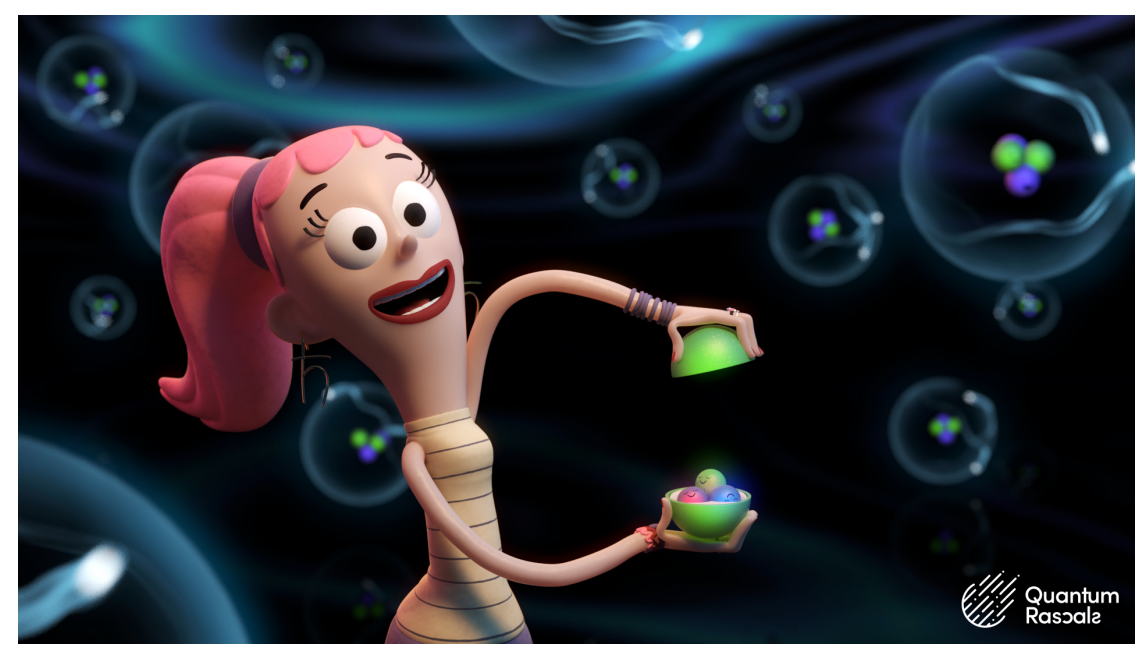

Figure 1: Looking into a proton with Quantum Kate. From Quantum Kate: What atoms are made of. [1].

\section{Quantum Kate}

Teenagers love to play with their friends and spend hours watching their favourite YouTubers. That is the reason why Quantum Kate came to life. She is the typical teenager sharing their curiosity and issues and is madly in love with Matthew. Additionally the use of cartoons adds flexibility, frees our imagination, and gives the opportunity to visualise even the quantum world. The idea of short cartoons featuring a lead female teenager came to one of us (Francesco). To bring to life Quantum Kate (KvanteKarina in Danish) took around one year and it involved professional script-writers and well known animators. They watched, not without pain, many well known teenage YouTubers to learn their language and their way to communicate. We therefore embraced social media and elevated their content. Quantum Kate became the first animated teenage YouTuber to speak about the quantum world.

Quantum Kate is not only a typical teenager but she is also into fashion (she loves it), like many girls her age. 


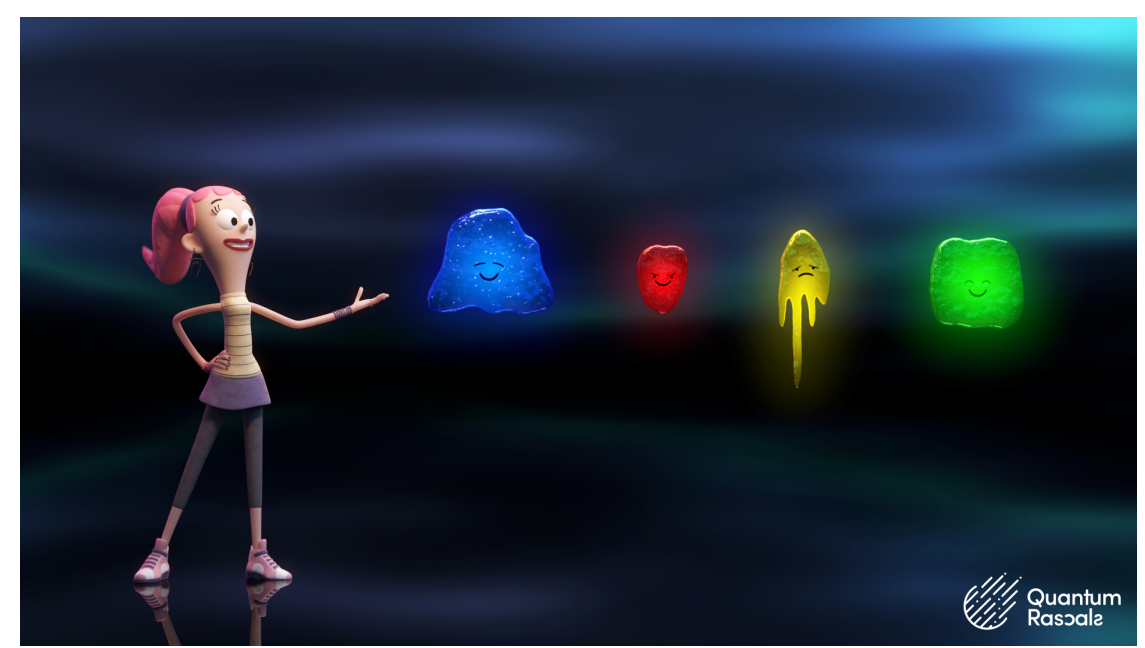

Figure 2: The four forces of the Standard model of particle physics. From Quantum Kate: The Standard Model [2].

Fashion, like physics are two of Quantum Kate's main interests, and she is super happy to share her knowledge of physics with her followers. She introduces them to the quantum world as well as black holes, stars, dark matter, the standard model of particle interactions, etc. These are concepts that are considered hard to communicate. Quantum Kate's starting point is often taken from her everyday life. In about one minute she introduces us to the amazing wonders of the subatomic world. Currently there are 17 episodes and two more will be released soon.

You will notice that, in each episode, Quantum Kate tells a bit about herself and her problems, thereby inviting the viewers into her life. She is their friend and confidant. Especially on her Danish YouTube site you will notice that teenagers send likes, add comments and ask questions. They interact with her as if she were a real YouTuber. By relating physics problems to her everyday life, Quantum Kate demystifies concepts that are far away from a teenage life.

The original 12 episodes of KvanteKarina are translated and dubbed from Danish to ten other languages. These are English, French, Spanish, Italian, Chinese, German, Norwegian, Swedish, Finnish and Icelandic.

Quantum Kate cannot replace standard teaching, she can, however help the teachers gain the attention of their pupils.

Beyond Quantum Kate, our activities at Quantum Rascals include giving talks to children and teenagers at schools, high schools and kindergartens (from 4 year-old). The topics and level are adjusted according to the specific age group and for the groups of age 12+ they are mostly build around one or more of the videos. This gives a perfect starting point for the talks and also brings variety into them.

\section{Quantum Kate on Youtube in numbers}

When released in the fall of 2017 the Danish KvanteKarina Youtube channel received much attention from Danish media and was at the same time introduced to our target group by a young YouTuber and influencer. The channel quickly gained a few thousand subscribers, a solid viewer 


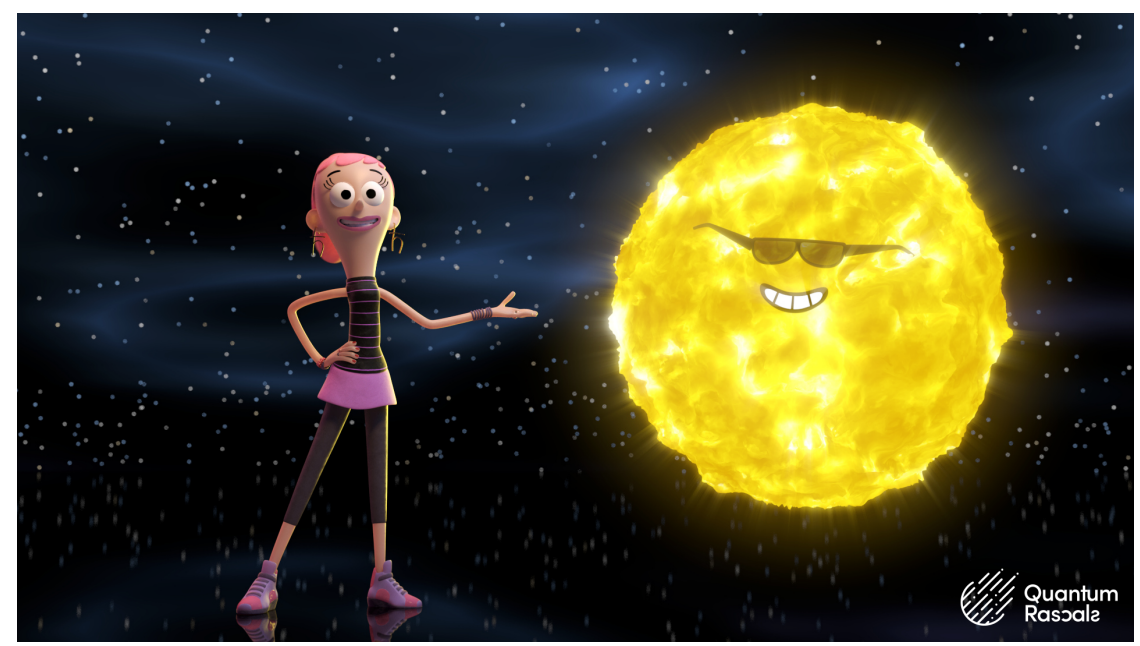

Figure 3: Do you know where the sun gets its energy from? Have a look inside the sun with Quantum Kate. From Quantum Kate: Sunshine [3].

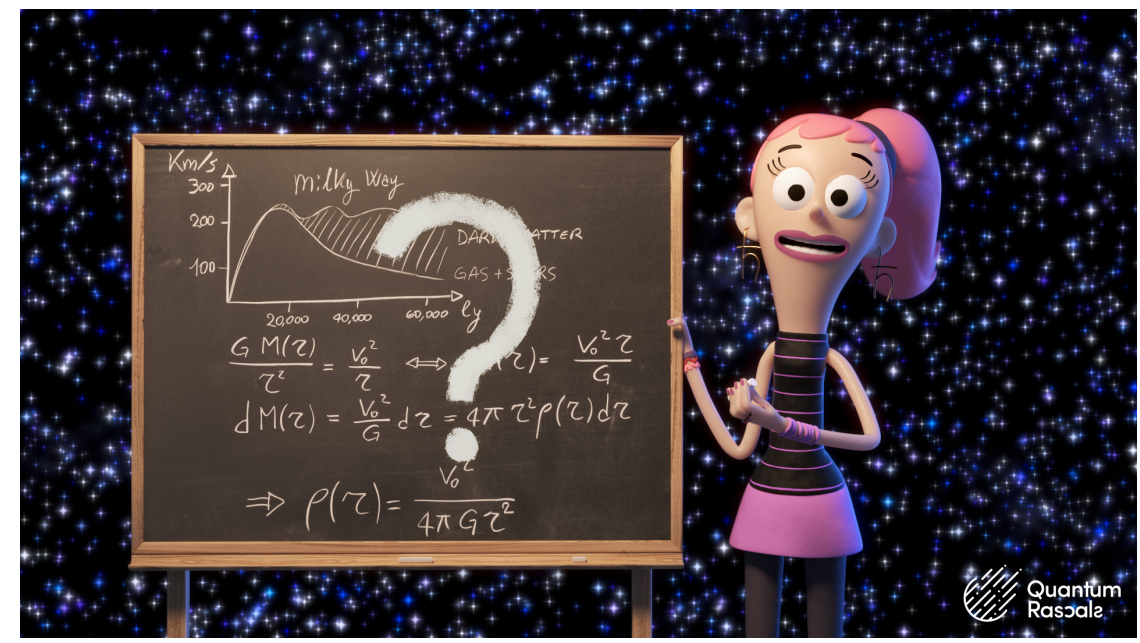

Figure 4: Matter is missing in our universe. Quantum Kate: Darkness everywhere [4].

base to begin with. Within the first year, the number of subscribers has climbed to more than 6,000 and the videos have been watched nearly 300,000 times.

The international channels were released in the spring of 2018 making it now possible for teenagers worldwide to become friends of Quantum Kate.

\section{Material \& Links}

Visit the world of Quantum Kate on our web page or find her on Youtube:

- www.kvantebanditter.dk/en/quantumkate

- www. youtube.com/kvantekarina (orignal in Danish) 


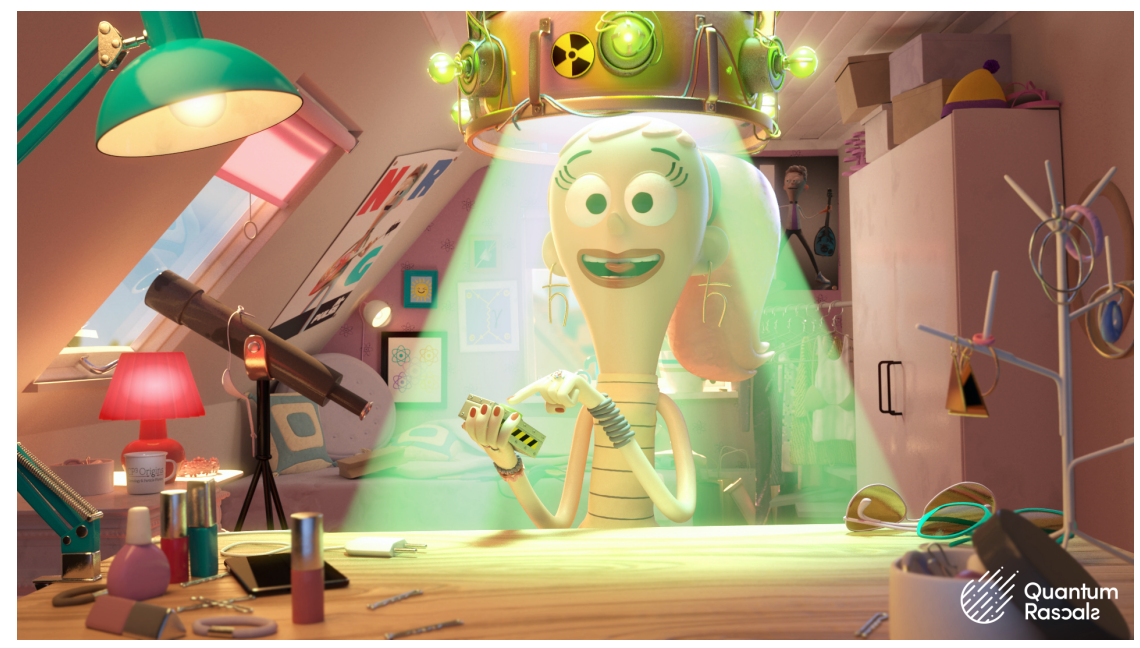

Figure 5: First time through the portal. From Quantum Kate: What atoms are made of [1].

- www. youtube.com/channel/UCokWdMzX-VJoP3UqlyEjPoA (Quantum Kate in English)

\section{Acknowledgements}

Quantum Rascals and Quantum Kate have been supported with 4 mio. DKK by A.P. Møller og Hustru Chastine Mc-Kinney Møllers Fond til Almene Formaal.

\section{References}

[1] What atoms are made of: www youtube.com/watch? $\mathrm{y}=$ SWQcqi zLAMU

[2] The standard model: www . youtube. com/watch? $\mathrm{v}=\mathrm{kOF} 0 \mathrm{CldtwdI}$

[3] Sunshine: www youtube.com/watch?v=xKrA-FFs Gdc

[4] Darkness everywhere: www . youtube. com/wat ch?v=120fARA $5 \times$ MA 